Article

\title{
Energy Efficiency Analysis of Fixed-Speed Pump Drives with Various Types of Motors
}

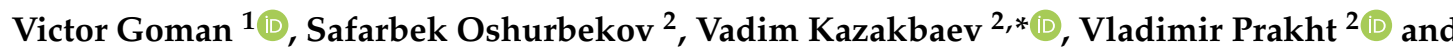 \\ Vladimir Dmitrievskii ${ }^{2}$ (D) \\ 1 Nizhniy Tagil Technological Institute, Ural Federal University, 622000 Nizhniy Tagil, Russia; \\ v.v.goman@urfu.ru \\ 2 Department of Electrical Engineering and Electric Technology Systems, Ural Federal University, \\ 620002 Yekaterinburg, Russia; s.oshurbekov@mail.ru (S.O.); va.prakht@urfu.ru (V.P.); \\ vladimir.dmitrievsky@urfu.ru (V.D.) \\ * Correspondence: vadim.kazakbaev@urfu.ru; Tel.: +7-343-375-45-07
}

Received: 10 November 2019; Accepted: 30 November 2019; Published: 4 December 2019

Featured Application: The presented results can be used to assess the energy-saving potential of general purpose and industrial electric motors of various types in various applications of electric drives.

\begin{abstract}
The paper presents a comparative analysis of energy consumption by $2.2 \mathrm{~kW}$ electric motors of various types and energy efficiency classes in the electric drive of a pump unit with throttle control in a water supply system. Line-start permanent-magnet synchronous motors of the IE4 energy efficiency class and induction motors of the IE4 and IE3 energy efficiency classes of various manufacturers were considered (IE4 and IE3 are labels of energy efficiency classes of electric motors according to IEC 60034-30-1 standard). Energy consumption at a hydraulic load changing under a typical duty cycle was calculated based on the nameplate data of the pump and electric motors. The developed method shows that selecting an electric motor based on the IE energy efficiency class under the IEC 60034-30-1 standard (i.e., based on efficiency at a rated load) may not provide the minimum energy consumption of a variable flow pump unit over a typical duty cycle. In particular, the considered IE4 class line-start permanent-magnet synchronous motors do not provide significant advantages over IE4 class induction motors, and sometimes even over IE3 class induction motors when they are used in variable flow pump units.
\end{abstract}

Keywords: centrifugal pump; energy efficiency; energy efficiency class; induction motor; line-start permanent-magnet synchronous motor; throttling control

\section{Introduction}

Despite the high efficiency and the high dynamic and static performance of variable speed drives (VSDs), electric motors powered directly from the mains are widely used in many applications due to the high cost of frequency converters. For instance, the market share of variable-speed drives is estimated to be about 30\% in Germany according to the European Commission data [1] and about 20\% in Switzerland according to the study disclosed in Phillips and Tieben [2].

In particular, such widely used machines, including centrifugal pumps, compressors, and fans, do not require a wide adjustment range, high starting torque, or high speed. Therefore, induction motors (IMs) powered directly from the mains are widely used in the drives of the above-mentioned fluid machinery. Furthermore, several manufacturers offer line-start permanent-magnet synchronous 
motors (LSPMSM) of a high energy efficiency class powered directly from the mains. The adjustment of fluid flow in this case is carried out using throttle control valves.

According to the data from the International Energy Agency [3], electric motors consume $46 \%$ of the world's electricity. They account for about $70 \%$ of the total industrial electricity consumption. According to the report of the European Commission [3], pump systems consume almost $22 \%$ of all electric energy generated throughout the world, as shown in Figure 1. Therefore, it is a pressing task to study the possibilities of increasing the energy efficiency of pump units. Improvements in energy efficiency of a pump unit can be provided by implementing changes in the hydraulic network in which the unit operates by using control systems, including a variable-speed drive, by optimizing and distributing the load (when units run in parallel), as well as by proper selection of the unit parts, in particular, via the use of electric motors of a higher energy efficiency class [4]. The latter method is considered in Shankar et al. [4] as the most relevant method for pumps under throttle control.

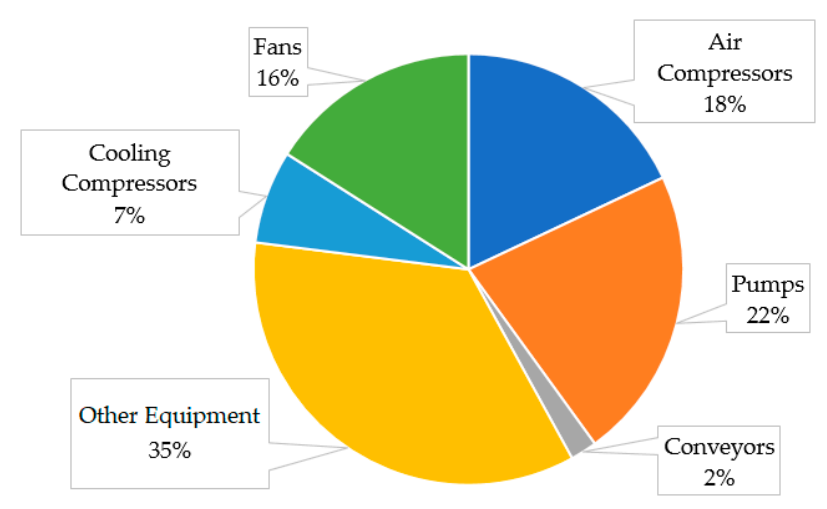

Figure 1. Energy consumption of various applications [5].

The minimum energy efficiency level for electric motors is defined in Annex I of European Commission [5]. Energy efficiency classes of line operated AC motors are determined in IEC 60034-30-1 standard [6]. In accordance with the EC regulation [5], since 1 January 2017, all electric motors with power ranging from 0.75 to $375 \mathrm{~kW}$ must have an energy efficiency class of at least IE3, or IE2 if they are used as part of a VSD (E4, IE3 and IE2 are labels of energy efficiency classes of electric motors according to IEC 60034-30-1 standard). Within the planned timeframe, according to Policy Option 4 [7], the introduction of the minimum acceptable energy efficiency class of at least IE4 is expected before 2030.

The classification of electric motors in References $[5,6]$ takes into account only the motor rated efficiency specified by the rated shaft power, but not the motor efficiency at underload modes, which is of at least comparable relevance for motors used as components of pump units [8].

In practice, most of the time, the centrifugal pump is employed at low or medium loads. However, the pumps are designed and integrated to satisfy maximal load conditions [9]. Also, it is estimated in Shuvalova [10] that $75 \%$ of the centrifugal pumps are oversized, many by more than $20 \%$. In Glover and Lukaszczyk [11], it is estimated that only $20 \%$ of the pump drive motors in operation are running at their rated mode. References $[12,13]$ provide comparisons of energy consumption by a pump unit with electric motors of various types and IE classes with a VSD because the frequency adjustment provides significant energy savings, especially under a low load. Nevertheless, since the electric drives with a direct supply still prevail in many industries, a number of studies provide comparisons between characteristics of electric motors operating directly from the mains. For instance, Mutize and Wang [14] provides a comparative analysis of the IM of the IE3 energy efficiency class and LSPMSM for fan applications in start-up and steady-state modes. The analysis shows that the steady-state efficiency and power factor of the LSPMSM are significantly higher than that of the IM. However, the analysis was performed at the rated load. The operation of the LSPMSM as part of a pump unit is given in Li et al. [15]. The design of the $2.2 \mathrm{~kW}$ IM and LSPMSM and their characteristics in steady-state and transient modes in the case of the rated load and without load are provided in 
Kahrisangi et al. [16]. At the rated power mode, a factor of annual cost savings in the case of replacing the IM by the LSPMSM is determined.

One of the main conclusions drawn in References [14-16] is the apparent advantage of LSPMSMs over IMs based on parameters such as efficiency and power factor. However, it should be noted that in said publications, the comparison between IMs and LSPMSMs was performed mainly for the rated modes.

The IE class of an electric motor is determined by its efficiency in the rated mode, in accordance with the IEC 60034-30-1 standard [6]. On the other hand, in heating, ventilation, and air conditioning (HVAC) applications, electric motors run in the rated mode for only a small fraction of the overall operation time.

The present paper discusses operating modes of IMs and LSPMSMs as part of a pump unit with a variable load depending on instantaneous water consumption, for example, in an HVAC application. The paper includes the energy consumption calculations for electric drives at loads different from the rated load of the electric motor, and a comparison of the obtained data in order to assess the energy-saving potential of electric motors of the IE3 and IE4 energy efficiency classes.

The main purpose of the present paper is to determine the criterion for selecting electric motors based on the condition of minimum energy consumption by considering a duty cycle of centrifugal pump units.

\section{Characteristics of the Pump Unit and the Motors}

The structure of the drive of a pump unit with one electric motor, powered directly from the mains, is shown in Figure 2 [8]. The electric motor is fed directly from the mains and coupled to a centrifugal pump without intermediate mechanical gears.

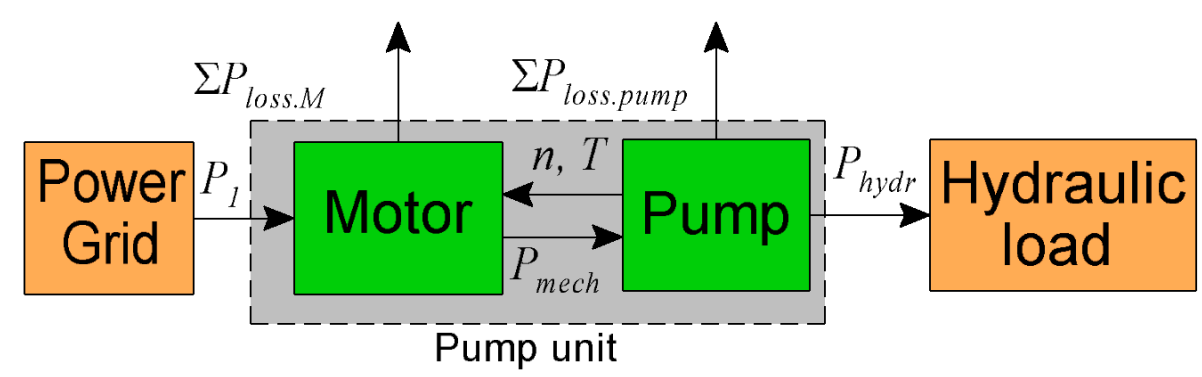

Figure 2. Schematic representation of a single pump unit for fixed-speed operation [8].

The input electrical power from the mains $P_{1}$ is converted by the electric motor into the mechanical power (output power) $P_{\text {mech }}$. Power $P_{\text {mech }}$ is less than $P_{1}$ by the value of the electric motor loss [8]:

$$
P_{\text {mech }}=P_{1}-\Sigma P_{\text {loss.M }}
$$

where $\Sigma P_{\text {loss. } M}$ is the sum of the motor losses.

The mechanical power $P_{\text {mech }}$ of the electric motor is transmitted to the pump, and therefore, in the absence of intermediate mechanical gears, is equal to the input mechanical power of the pump. In the pump, the mechanical power $P_{\text {mech }}$ is converted to the hydraulic power $P_{h y d r}$. The difference between $P_{\text {mech }}$ and $P_{\text {hydr }}$ is the total loss $\Sigma P_{\text {loss.pump }}$ in the pump [8]:

$$
P_{\text {hydr }}=P_{\text {mech }}-\Sigma P_{\text {loss.pump }} \text {. }
$$

The hydraulic power is determined using the flow $Q$ and the pump head $H_{\text {pump }}$. The pump head depends on the flow in accordance with the $Q-H$ coefficient of the pump at a given pump rotational speed $n$.

The required electrical power $P_{1}$ depends on the flow $Q$ [8]:

$$
P_{1}=\rho \cdot g \cdot Q \cdot H_{\text {pump }}+\Sigma P_{\text {loss.pump }}+\Sigma P_{\text {loss.M }}
$$


In order to compare the energy consumption of the electric motors of the pump unit when adjusting flow using a throttle valve, a centrifugal pump NM4 40/25B (manufactured by Calpeda S.p.A., Montorso Vicentino, Vicenza, Italy) with the rated power $P_{R A T E}=2.2 \mathrm{~kW}$ and with rated rotational speed $n=1450 \mathrm{rpm}$ [17] was considered. Pump data is shown in Table 1. $Q_{B E P}$ denotes the flow at the best efficient point (BEP), and $H_{B E P}$ denotes the pump head at BEP.

Table 1. Nameplate data of the pump.

\begin{tabular}{ccccccc}
\hline Parameter & Type & $\boldsymbol{P}_{\text {RATE }}(\mathrm{W})$ & $\boldsymbol{n}(\mathbf{r p m})$ & $\boldsymbol{Q}_{\text {BEP }}\left(\mathrm{m}^{\mathbf{3}} / \mathbf{h}\right)$ & $\boldsymbol{H}_{\text {BEP }}(\mathrm{m})$ & Efficiency $(\%)$ \\
\hline Value & NM4 40/25B & 2200 & 1450 & 19 & 17.8 & 60 \\
\hline
\end{tabular}

The calculation was performed for eight different four-pole electric motors with a power of $2.2 \mathrm{~kW}$, namely three LSPMSMs of the IE4 class (Bharat Bijlee SynchroVERT [18], WEG [19], SEW-Eurodrive [20]), two IMs of the IE4 class (Siemens [21] and WEG [22]), and three IMs of the IE3 class (Siemens [21], WEG [23], and ABB [24]). Efficiency data for the electric motors are shown in Table 2.

Table 2. Efficiency of $2.2 \mathrm{~kW}$ four-pole electric motors.

\begin{tabular}{|c|c|c|c|c|c|}
\hline \multirow{2}{*}{$m$} & \multirow{2}{*}{ Type of Motor } & \multirow{2}{*}{ Efficiency Class } & \multicolumn{3}{|c|}{ Efficiency (\%) at the Various Loads } \\
\hline & & & $50 \%$ & $75 \%$ & $100 \%$ \\
\hline 1 & LSPMSM SEW DRU J & IE4 & 88.0 & 90.5 & 91.2 \\
\hline 2 & LSPMSM SynchroVERT & IE4 & 88.6 & 89.4 & 89.5 \\
\hline 3 & LSPMSM WEG WQuattro & IE4 & 86.0 & 89.0 & 90.2 \\
\hline 4 & IM Siemens 1LE1004 & IE4 & 88.3 & 89.6 & 89.5 \\
\hline 5 & IM WEG W22 & IE4 & 88.5 & 89.5 & 89.5 \\
\hline 6 & IM Siemens 1LE1003 & IE3 & 86.4 & 87.3 & 86.7 \\
\hline 7 & IM WEG W21 & IE3 & 86.5 & 87.0 & 87.0 \\
\hline 8 & IM ABB M3BP & IE3 & 85.1 & 86.9 & 86.7 \\
\hline
\end{tabular}

\section{Assessment of the Energy Consumption of the Pump Unit}

The operation of the pump unit was considered in modes wherein water flow over the duty cycle changed in accordance with the typical characteristic of HVAC applications. A typical pump duty cycle (Figure 3) defined by EC regulations [25] is characterized by four modes. A notable feature of this cycle is that, most of the time, the pump operates at a flow rate much less than the rated value. For example, with the flow of $25 \%$ of the rated value, the pump operates for the fraction of time $t_{i} / t_{\Sigma}=$ $44 \%$ where $t_{\Sigma}$ is the total operation time taken to be equal to $24 \mathrm{~h}$ and $t_{i}$ is the pump operation time in the said mode. Herein, the fraction of the operation time in the rated mode did not exceed $6 \%$. Such a flow-time profile is typical for systems with widely varying demand of flow rate, i.e., for variable flow systems [5].

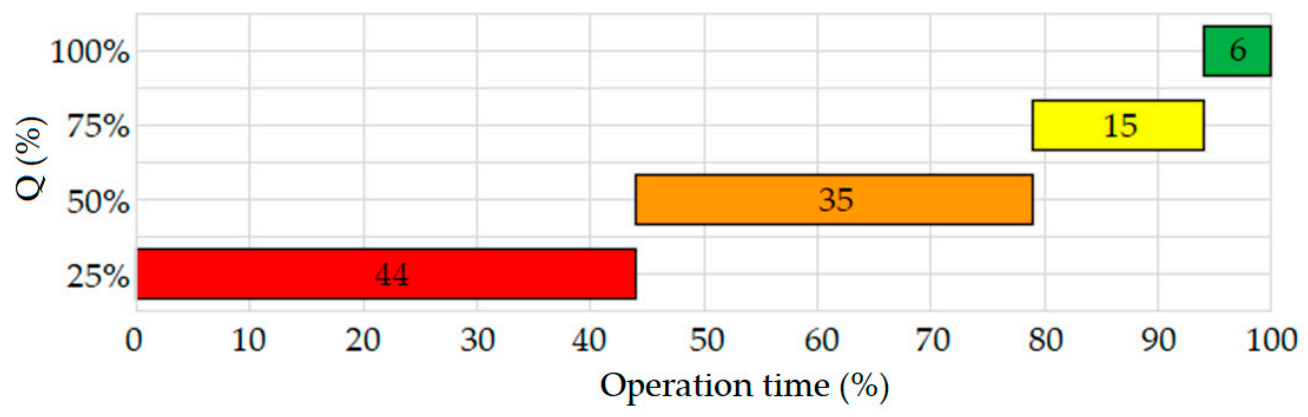

Figure 3. Time dependence of water consumption per cycle. 
The electric motor was connected directly to the mains, i.e., motor speed was not adjusted using a frequency converter over the course of the cycle, and the flow $Q$ of the pump was adjusted using a throttle. In this case, the water pressure changed in accordance with the $Q-H$ curve of the pump, and the operating point was the intersection point of the pump characteristic and the hydraulic system characteristic. Figure 4 shows the interpolation results of the $Q-H$ characteristic of the selected pump and the starting points, according to manufacturer data [17].

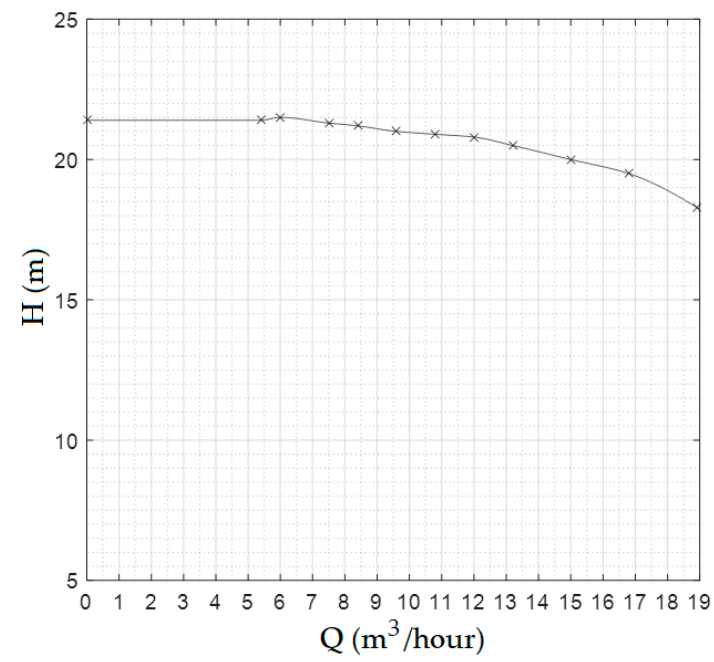

(a)

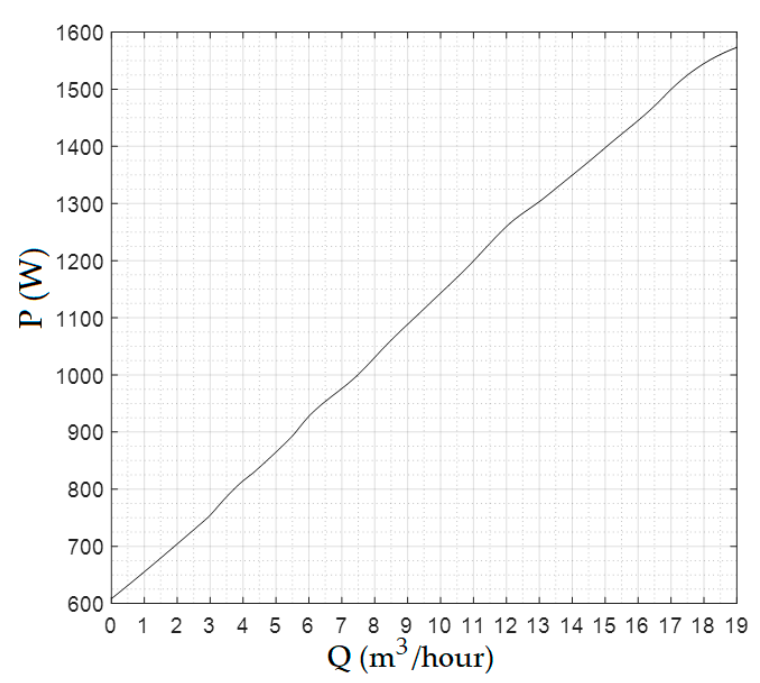

(b)

Figure 4. (a) $Q-H$ curve of the pump. (b) Dependence of the pump power on water flow [17].

The mechanical (input) power curve of the pump as a function of flow is reported by the pump manufacturer (Figure $4 \mathrm{~b}$ ). From the curve, the pump power was determined in four operation modes ( $25 \%, 50 \%, 75 \%$, and $100 \%$ of the flow). The flow corresponding to $100 \%$ was determined based on the pump efficiency curve [17], corresponding to maximum efficiency. Based on the known nameplate data, the efficiencies of the electric motors (Table 2) at the four operation modes of the pump unit were determined using polynomial interpolation of the loss curve $\Sigma P_{\text {loss.M }}$ of each electric motor. As seen in Ferreira and De Almeida [26], the correlation between the electric motor loss and load is described well using a second-order polynomial, the coefficients of which can be easily obtained from the efficiencies at three points provided by the electric motors manufacturers.

The obtained efficiency values are provided in Table 3, which also shows the following values for each operating mode: flow, pump head, and mechanical output power of the electric motors as percentages of the rated output. It can be observed that the pump ran in underload modes $(Q<100 \%)$ for most of the time. It was assumed that the head varied according to the $Q-H$ curve of the pump (Figure 4a).

The real electric power consumed from the mains in each mode was calculated according to Equation (4):

$$
P_{1 . i . m}=P_{\text {mech.i.m }} / \eta_{\text {M.i.m }}
$$

where $\eta_{\text {M.i.m }}$ is the efficiency of the $m$ th motor in the $i$ th mode of operation. Calculation results are given in the Table 4 .

The daily energy consumption for each electric motor over a full duty cycle of the pump unit in accordance with the corresponding load profile was determined using the Equation (5).

$$
E_{d . m}=t_{\Sigma} \cdot \sum_{i=1}^{4}\left(P_{1 . i . m} \cdot \frac{t_{i}}{t_{\Sigma}}\right)
$$


For the year-round operation of the pump unit, the annual energy consumption was calculated as follows:

$$
E_{y \cdot m}=E_{d . m} \cdot 365
$$

Table 3. Interpolated values of efficiency of electric motors.

\begin{tabular}{ccccc}
\hline Mode Number $\boldsymbol{i}$ & $\mathbf{1}$ & $\mathbf{2}$ & $\mathbf{3}$ & $\mathbf{4}$ \\
\hline Operation time (\%) & 44 & 35 & 15 & 6 \\
Operation time (h/day) & 10.56 & 8.4 & 3.6 & 1.44 \\
$Q_{i}(\%)$ & 25 & 50 & 75 & 100 \\
$Q_{i}\left(\mathrm{~m}^{3} / \mathrm{h}\right)$ & 4.75 & 9.50 & 14.25 & 19.00 \\
$H_{\text {pump. } i}(\%)$ & 120 & 118 & 113 & 100 \\
$H_{\text {pump.i }}(\mathrm{m})$ & 21.4 & 21.0 & 20.2 & 17.8 \\
$P_{\text {mech. }}(\mathrm{W})$ & 851 & 1116 & 1361 & 1573 \\
$P_{\text {mech }}$ i $(\%)$ & 38.7 & 50.7 & 61.9 & 71.5 \\
& & Efficiency & $\eta_{\text {M.i.m }} \mathbf{( \% )}$ & \\
\hline 1. LSPMSM SEW DRU J & 85.5 & 88.1 & 89.5 & 90.3 \\
2. LSPMSM SynchroVERT & 87.7 & 88.6 & 89.1 & 89.3 \\
3. LSPMSM WEG WQuattro & 83.3 & 86.1 & 87.8 & 88.7 \\
4. IM Siemens 1LE1004 & 86.7 & 88.4 & 89.2 & 89.5 \\
5. IM WEG W22 & 85.8 & 88.2 & 89.3 & 89.7 \\
6. IM Siemens 1LE1003 & 84.9 & 86.5 & 87.1 & 87.3 \\
7. IM WEG W21 & 84.8 & 86.3 & 86.9 & 87.2 \\
8. IM ABB M3BP & 82.7 & 85.2 & 86.3 & 86.8 \\
\hline
\end{tabular}

Table 4. Power consumption $P_{1 . i, m}(\mathrm{~W})$.

\begin{tabular}{ccccc}
\hline Type of Motor & $\mathbf{1}$ & $\mathbf{2}$ & $\mathbf{3}$ & $\mathbf{4}$ \\
\hline 1. LSPMSM SEW DRU J & 996.2 & 1266.1 & 1520.3 & 1742.3 \\
2. LSPMSM Synchro-VERT & 971.3 & 1258.6 & 1527.4 & 1760.8 \\
3. LSPMSM WEG WQuattro & 1022.6 & 1295.2 & 1550.9 & 1773.1 \\
4. IM Siemens 1LE1004 & 982.2 & 1262.0 & 1526.3 & 1757.5 \\
5. IM WEG W22 & 992.9 & 1264.8 & 1524.4 & 1753.8 \\
6. IM Siemens 1LE1003 & 1003.1 & 1289.9 & 1562.5 & 1802.5 \\
7. IM WEG W21 & 1004.4 & 1293.1 & 1566.0 & 1805.0 \\
8. IM ABB M3BP & 1029.4 & 1309.4 & 1576.4 & 1812.2 \\
\hline
\end{tabular}

The cost of electricity consumed (in Euro), considering the accepted grid tariffs GT $=0.1987 € / \mathrm{kW} \cdot \mathrm{h}$ for non-household consumers [27] for Germany in the second half of 2018, was calculated as follows:

$$
C_{y \cdot m}=E_{y \cdot m} \cdot G T \text {. }
$$

We also assessed the energy consumption during the whole life cycle of the pump system, which is usually 15-20 years [28,29]. We defined the energy cost for the lifespan of $n=20$ years without taking into account the maintenance costs and the initial cost of the motors since the market cost of the motors depends on many factors and this was beyond of the topic of the present paper. Besides, the pump lifetime cost often consists mostly of the energy cost $(>50-60 \%)[28,29]$.

The net present value (NPV) of the lifecycle cost was calculated as follows:

$$
C_{\text {LCCen.m }}=C_{y \cdot m} /(1+(y-p))^{n}
$$

where $y$ is the interest rate (assumed to be 0.04) and $p$ is the expected annual inflation (assumed to be $0.02)[28,29]$.

In order to correlate the cost of electricity consumed with using various electric motors in pump units, the differences between the costs of electricity required by the electric motor with the highest 
energy consumption (IE3 class motor No. 8 manufactured by ABB, Zürich, Switzerland) and the other seven motors were calculated according to Equation (9). The calculation results according to Equations (4)-(9) are summarized in Tables 4 and 5, and are also shown in Figures 5 and 6.

$$
S_{y \cdot m}=C_{y \cdot 8}-C_{y \cdot(1 \ldots 7)}
$$

Table 5. Cost characteristics of the power consumption.

\begin{tabular}{cccccc}
\hline Type of Motor & $\boldsymbol{E}_{\boldsymbol{d} \cdot \boldsymbol{m}} \mathbf{( k W \cdot h )}$ & $\boldsymbol{E}_{\boldsymbol{y} \cdot \boldsymbol{m}} \mathbf{( k W \cdot h )}$ & $\boldsymbol{C}_{\boldsymbol{y} \cdot \boldsymbol{m}}(\mathbf{\epsilon})$ & $\boldsymbol{C}_{\text {LCCen.m }}(\mathbf{k \epsilon )}$ & $\boldsymbol{S}_{\boldsymbol{y} \cdot \boldsymbol{m}}(\boldsymbol{\epsilon})$ \\
\hline 1. LSPMSM SEW DRU J & 29.1 & 10,635 & 2113.1 & 34.55 & 73.8 \\
2. LSPMSM SynchroVERT & 28.9 & 10,535 & 2093.3 & 34.23 & 93.6 \\
3. LSPMSM WEG WQuattro & 29.8 & 10,882 & 2162.3 & 35.36 & 24.6 \\
4. IM Siemens 1LE1004 & 29.0 & 10,585 & 2103.1 & 34.39 & 83.8 \\
5. IM WEG W22 & 29.1 & 10,630 & 2112.1 & 34.54 & 74.8 \\
6. IM Siemens 1LE1003 & 29.6 & 10,822 & 2150.3 & 35.16 & 36.6 \\
7. IM WEG W21 & 29.7 & 10,843 & 2154.4 & 35.23 & 32.5 \\
8. IM ABB M3BP & 30.2 & 11,006 & 2186.9 & 35.76 & 0 \\
\hline
\end{tabular}

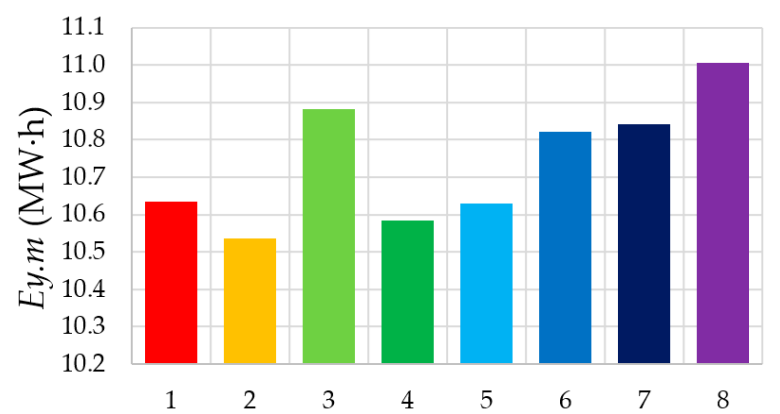

(a)

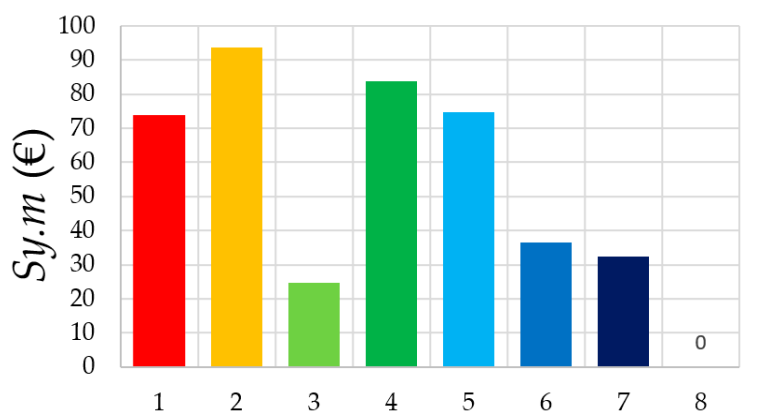

(b)

Figure 5. (a) Annual energy consumption. (b) Energy cost savings over electric motor No. 8. 1-LSPMSM IE4 SEW DRU J; 2-LSPMSM IE4 Synchrovert; 3-LSPMSM IE4 Weg WQuattro; 4-IM IE4 Siemens 1LE1004; 5-IM IE4 Weg W22; 6-IM IE3 Siemens 1LE1003; 7-IM IE3 Weg W21; 8-IM IE3 ABB M3BP.

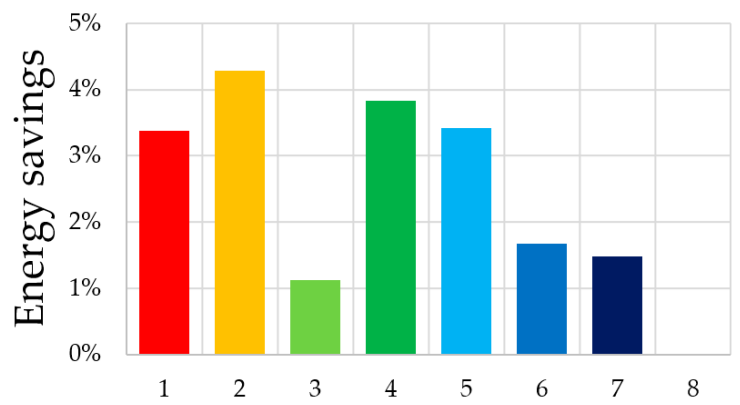

Figure 6. Energy cost savings over electric motor No. 8 (for numbers of the motors see the caption of Figure 5).

Figure 5 shows that the electric motor 3 (LSPMSM of the IE4 the class) consumed more electricity than IMs 6 and 7 of the IE3 class in the considered duty cycle, but less electricity than IM 8 of the IE3 class. Thus, the said IE4 class electric motor provided lower cost savings compared to the IE 3 class electric motors 6 and 7. LSPMSMs 1 and 2 had energy consumptions approximately matching those of IMs 4 and 5 of the IE4 class. The lowest energy consumption was exhibited by electric motor 2 (SynchroVERT LSPMSM) and the greatest energy consumption was exhibited by electric motor 8 (IM by $A B B$ ). 
The results shown in Figure $5 a, b$ are a consequence of the fact that, according to the adopted standard [6], electric motors are classified in accordance with the efficiency in the rated mode (a load of $100 \%$ ). However, in pump units, electric motors run at 2-4 times lower power than their rated value for a significant part of the time, and as a result, exhibit a reduced efficiency. At the same time, the existing standards do not establish the minimum efficiencies at loads below the rated value for electric motors powered directly from the mains. Thus, the selection of an electric motor based on its IE energy efficiency class will not necessarily result in minimum energy consumption in a number of applications, such as variable flow pumps. It should be noted that for frequency-controlled electric motors, the IEC 60034-30-2 standard [30] establishes the efficiencies in seven load modes different from the rated mode. In the draft version of the IEC 60034-30-2 standard [31], it was proposed that the total efficiency be calculated for frequency-controlled electric motors of pumps and fans (drives with a quadratic torque-speed dependence) as the average efficiency coefficient at reduced speeds and loads. Figure 6 shows the energy cost savings over the worst case of electric motor No. 8 (in \%).

Therefore, when selecting an electric motor for a pump unit operating with a variable flow, one should not be guided only by the IE energy-efficiency class and the rated efficiency value; instead, one should calculate the energy consumption depending on the operating conditions or should take into account the energy efficiency index of the pump unit (see Section 4).

It is worth noting that LSPMSMs have a higher cost compared to IMs (especially IE3 class) due to the use of expensive rare-earth magnets in its design. The process of obtaining rare-earth elements from raw ore is associated with significant environmental damage, and in de Lima [32], it is claimed that the production of each ton of rare-earth element material results in the generation of 1-1.4 tons of radioactive waste.

Only a small part of the resulting slush contains rare-earth elements and is subsequently extracted for refinement [32]. There is also a technological dependence on rare-earth element suppliers from China, as more than $95 \%$ of the world's rare-earth element mining is controlled by China [33]. In the current situation on the market, the prices of rare-earth elements are unstable and can change several times over several years [34].

Also, the difficulty in starting up LSPMSMs at a significant load moment of inertia severely limits their potential applications. A review of modern papers on LSPMSMs [35-39] shows that the maximum moment of inertia of the load for such electric motors is relatively small and insufficient to start up and reach the rated speed, for example, using a fluid machine with a steel impeller. Such electric motors cannot be started with a large number of typical mechanisms, such as reciprocating compressors, screw compressors, plunger pumps, conveyors, escalators, etc. [35-38].

According to the results of the comparison between LSPMSMs and IMs of classes IE3 and IE4 disclosed in Ferreira et al. [39], LSPMSMs have the highest start-up current peaks, increasing the possibility of nuisance tripping of typical magnetic circuit breakers. This high start-up current can damage contactors, fuses, and other protection devices. Also, using star-delta starters is not recommended or not possible in the case of an LSPMSM. In addition, a voltage decrease and unbalanced supply significantly deteriorate LSPMSM's performances [39].

It can be concluded that, taking into account the aforementioned disadvantages of LSPMSMs, the use of IE4 class IMs in the considered area of application is currently more justified.

\section{Assessment of the Energy Efficiency Index of the Pump Unit}

The energy efficiency of circulators operating primarily with a variable flow is evaluated in accordance with the EU regulation [25]. The profile indicated in Figure 3 and adopted as a typical pump load profile according to this document [25] is used to perform the calculations in Section 3. Stoffel [8] suggests that the energy efficiency index (EEI) that is already well-established for the assessment of energy efficiency of circulators can be used for other types of pumps and fluid machinery.

Thus, EEI is the most suitable indicator for assessing the energy efficiency of variable flow systems for various purposes, in contrast to the minimum efficiency index (MEI), which is based on 
efficiencies in a relatively limited range of operating points (75-110\% of the flow) [8] and is defined in the regulation [40].

According to the Europump association approach [41] (p. 12) and to Lang et al. [42], EEI is defined by the formula:

$$
E E I=P_{1 . \text { avg }} / P_{1 . r e f}
$$

where $P_{1 . a v g}$ is the average electric power consumed by the pump, which is determined using the following formula [41]:

$$
P_{1 . a v g}=\sum_{i=1}^{4}\left[\left(\frac{t_{i}}{t_{\Sigma}}\right) \cdot P_{1 . i}\right] .
$$

The denominator in Equation (10), $P_{1 . r e f}$, is the electric power of the reference system, which according to References [41,42], is determined using Equation (11):

$$
P_{1 . r e f}=P_{\text {hydr.ref }} /\left(\eta_{\text {motor.ref }}-\eta_{\text {pump.min.req }}\right),
$$

In both formulae, $P_{\text {hydr.ref }}$ is the hydraulic power of the reference system, which is defined as the product of flow $Q_{B E P}\left(\mathrm{~m}^{3} / \mathrm{s}\right)$ and pump head $H_{B E P}(\mathrm{~Pa})$.

In Equation (12), $\eta_{\text {motor.ref }}$ is the efficiency of the reference electric motor [6], which was taken to be equal to $86.7 \%$ as the corresponding efficiency of a four-pole $2.2 \mathrm{~kW}$ electric motor of IE3 energy efficiency class. $\eta_{\text {pump.min.req }}$ is the minimum required efficiency of the reference pump at the best efficiency point [40], which depends on the coefficient $C$ determined by the type of pump, the rated rotational speed $n$ of the pump and energy efficiency thereof, the flow $Q_{B E P}$, and the specific speed $n_{s}$, which in turn depends on $H_{B E P}$ and $n$. A detailed calculation of $\eta_{\text {pump.min.req }}$ is not provided in the present document.

Calculation results for Equations (10)-(12) are shown in Table 6.

Table 6. Energy efficiency indexes.

\begin{tabular}{cccc}
\hline $\boldsymbol{m}$ & Type of Motor & $\boldsymbol{P}_{\mathbf{1 . a v g}}(\mathbf{W})$ & EEI \\
\hline 1 & LSPMSM SEW DRU J & 1214 & 0.5786 \\
2 & LSPMSM SynchroVERT & 1203 & 0.5732 \\
3 & LSPMSM WEG WQuattro & 1242 & 0.5921 \\
4 & IM Siemens 1LE1004 & 1208 & 0.5759 \\
5 & IM WEG W22 & 1213 & 0.5784 \\
6 & IM Siemens 1LE1003 & 1235 & 0.5888 \\
7 & IM WEG W21 & 1238 & 0.5899 \\
8 & IM ABB M3BP & 1256 & 0.5988 \\
\hline
\end{tabular}

By observing the data in Table 6, it is evident that the EEI values for a pump unit with various electric motors corresponds to the patterns made apparent in Figure 5a,b. Therefore, EEI characterizes the energy consumption of a pump unit more objectively than the energy efficiency class (IE) of the electric motor, which depends only on the efficiency in the rated mode.

It should be noted that for circulators subject to the EC regulation [25], since 2005, there has been a voluntary labeling of products by members of the Europump Association using the A-G letter grade for the energy efficiency class. The introduction of such labeling for industrial pump units may also be a consideration.

\section{Conclusions}

The present paper provides a comparative analysis of the energy consumption of electric motors of various types (LSPMSMs and IMs) and energy efficiency classes (IE3 and IE4) used as part of a $2.2 \mathrm{~kW}$ variable-speed pump unit with throttle control. The approach used for comparing the energy characteristics of electric motors is described, including the calculation of energy consumption by a 
pump unit in a typical duty cycle containing various hydraulic load values. Electric power values, energy consumption, and cost savings for eight electric motors were calculated.

According to the results of the calculation carried out using the disclosed method and performed on the basis of the nameplate data of electric motors and pumps, it was shown that the use of an electric motor with a higher efficiency at the rated load (high energy efficiency class, according to IEC 60034-30-1 standard [6]) does not always provide a lower energy consumption in pump units with variable fluid flow. The method further shows that the considered IE4 class LSPMSMs may not provide significant advantages over IE4 class IMs, and sometimes even over IE3 class IMs when they are used in variable flow fixed-speed applications.

Author Contributions: Conceptual approach, V.D. and V.P.; data curation V.G., V.D., and V.K.; software V.G. and V.K.; calculations and modeling, V.G, V.P., V.K., and S.O.; writing of original draft, V.G.,V.D, V.K., V.P., and S.O.; visualization, V.G., V.K., and S.O.; review and editing, V.G., V.D., V.K., and V.P.

Funding: The research was conducted as part of theme no. 8.9549.2017/8.9. within the frame of the government task of the Ministry of Education and Science of the Russian Federation regarding R\&D.

Conflicts of Interest: The authors declare no conflict of interest.

\section{References}

1. Almeida, A.; Ferreira, F.J.; Fong, J.; Fonseca, P. EuP Lot 11 Motors, Final report to the European Commission. 2008. Available online: https://circabc.europa.eu/sd/d/62415be2-3d5a-4b3f-b29a-d1760f4dc11a/Lot11\% 20Motors\%201-8\%20final\%2028-04-08.pdf (accessed on 27 November 2019).

2. Phillips, R.; Tieben, R. Improvement of Electric Motor Systems in Industry (IEMSI). In Proceedings of the Energy Efficiency in Motor Driven Systems (EEMODS '17), Rome, Italy, 6-8 September 2017.

3. European Commission. Study on Improving the Energy Efficiency of Pumps. 2001. Available online: http://www.jakob-albertsen.dk/komposit/Darmstadtrapport.pdf (accessed on 27 November 2019).

4. Shankar, V.K.A.; Umashankar, S.; Paramasivam, S.; Hanigovszki, N. A comprehensive review on energy efficiency enhancement initiatives in centrifugal pumping system. Appl. Energy 2016, 181, 495-513. [CrossRef]

5. European Commission Regulation (EC) No. 640/2009 Implementing Directive 2005/32/ EC of the European Parliament and of the Council with Regard to Ecodesign Requirements for Electric Motors, (2009), Amended by Commission Regulation (EU) No 4/2014 of January 6, 2014, Document 32014R0004. Available online: https://eur-lex.europa.eu/legal-content/EN/TXT/?uri=CELEX\%3A32014R0004 (accessed on 27 November 2019).

6. Rotating Electrical Machines-Part 30-1: Efficiency Classes of Line Operated AC Motors (IE Code); IEC 60034-30-1:2014; IEC: Geneva, Switzerland, 2014; Available online: https://webstore.iec.ch/publication/136 (accessed on 27 November 2019).

7. De Almeida, A.; Fong, J.; Falkner, H. New European Ecodesign Regulation Proposal for Electric Motors and Drives. In Proceedings of the Energy Efficiency in Motor Driven Systems (EEMODS '15), Helsinki, Finland, 15-17 September 2015.

8. Stoffel, B. Assessing the Energy Efficiency of Pumps and Pump Units. In Background and Methodology; Elsevier: Amsterdam, The Netherlands, 2015.

9. Gevorkov, L. Simulation and Experimental Study on Energy Management of Circulating Centrifugal Pumping Plants with Variable Speed Drives. Ph.D. Thesis, Tallinn University of Technology, Tallinn, Estonia, 2017.

10. Shuvalova, J. Optimal Approximation of Input-Output Characteristics of Power Units and Plants. Ph.D. Thesis, Tallinn University of Technology, Tallinn, Estonia, 2004.

11. Glover, A.; Lukaszczyk, M. Oversizing pump motors-The problems. World Pumps 2005, 2005, 36-38. [CrossRef]

12. Safin, N.; Kazakbaev, V.; Prakht, V.; Dmitrievskii, V. Calculation of the Efficiency and Power Consumption of Induction IE2 and Synchronous Reluctance IE5 Electric Drives in the Pump Application Based on the Passport Specification According to the IEC 60034-30-2. In Proceedings of the 25th International Workshop on Electric Drives: Optimization in Control of Electric Drives (IWED), Moscow, Russia, 31 January—2 February 2018. [CrossRef] 
13. Kazakbaev, V.; Prakht, V.; Dmitrievskii, V.; Ibrahim, M.; Oshurbekov, S.; Sarapulov, S. Efficiency Analysis of Low Electric Power Drives Employing Induction and Synchronous Reluctance Motors in Pump Applications. Energies 2019, 12, 1144. [CrossRef]

14. Mutize, C.; Wang, R. Performance comparison of an induction machine and line-start PM motor for cooling fan applications. Proc. SAUPEC 2013. [CrossRef]

15. Li, J.; Song, J.; Cho, Y. High Performance Line Start Permanent Magnet Synchronous Motor for Pumping System. IEEE Int. Symp. Ind. Electron. 2010. [CrossRef]

16. Kahrisangi, M.G.; Isfahani, A.H.; Vaez-Zadeh, S.; Sebdani, M.R. Line-start permanent magnet synchronous motors versus induction motors: A comparative study. Front. Electr. Electron. Eng. 2012, 2095-2732. [CrossRef]

17. NM, NMS. Close Coupled Centrifugal Pumps with Flanged Connections; Catalogue; Calpeda. 2018. Available online: https://www.calpeda.com/system/pdf/catalogue_en_50hz.pdf (accessed on 27 November 2019).

18. Catalogue of Super Premium Efficiency SynchroVERT LSPM Motors. Available online: https://www. bharatbijlee.com/media/14228/synchrovert_catalogue.pdf (accessed on 27 November 2019).

19. Wquattro $2.2 \mathrm{~kW} 4 \mathrm{P}$ 100L 3Ph 230/400 V $50 \mathrm{~Hz}$ IC411-TEFC-B3T. Product Details. Available online: https://www.weg.net/catalog/weg/RU/en/Electric-Motors/Special-Application-Motors/Permanent-MagnetMotors/Line-Start-PM-Motors/Wquattro-2-2-kW-4P-100L-3Ph-230-400-V-50-Hz-IC411---TEFC---B3T/p/ 13009386 (accessed on 27 November 2019).

20. Addendum to the Operating Instructions: AC Motors DR.71.J-DR.100.J with LSPM Technology, 21281793/EN, 09/2014, SEW Eurodrive. Available online: https://download.sew-eurodrive.com/download/pdf/21343799. pdf (accessed on 27 November 2019).

21. Catalog Siemens D81.1 Simotics GP, SD, XP, DP Low-Voltage Motors, 05/2018. Available online: https://support.industry.siemens.com/cs/attachments/109749197/Motors-D81.1-complete-English-07-2019. pdf?download=true (accessed on 27 November 2019).

22. W22 Super Premium Efficiency 3 HP 4P 182/4T 3Ph 208-230/460//380 V 60 Hz IC411-TEFC-Foot-Mounted. Product Details. Available online: https://www.weg.net/catalog/weg/MV/en/Electric-Motors/Low-VoltageNEMA-Motors/General-Purpose-ODP-TEFC/Cast-Iron-TEFC-General-Purpose/W22-Super-PremiumEfficiency/W22-Super-Premium-Efficiency-3-HP-4P-182-4T-3Ph-208-230-460-380-V-60-Hz-IC411--TEFC---Foot-mounted/p/12792146 (accessed on 27 November 2019).

23. Multimounting IE3 2.2 kW 4P 100L 3Ph 220-240/380-415//460 V 50 Hz IC411-TEFC-B3T. Product Details. Available online: https:/www.weg.net/catalog/weg/RU/en/Electric-Motors/Low-Voltage-IEC-Motors/ General-Purpose-ODP-TEFC/Aluminum-TEFC-General-Purpose/Aluminium-TEFC-General-Purpose/ Multimounting-IE3/Multimounting-IE3-2-2-kW-4P-100L-3Ph-220-240-380-415-460-V-50-Hz-IC411--TEFC---B3T/p/12397774 (accessed on 27 November 2019).

24. Catalog ABB_Low Voltage General Performance Motors. June 2018. Available online: https://library.e.abb. com/public/00389a1977844886b7e3e7560a6c22bf/9AKK105789\%20EN\%2006-2018\%20General\%20Perf.pdf (accessed on 27 November 2019).

25. Commission Regulation (EC) No 641/2009 of July 22, 2009 implementing Directive 2005/32/EC of the European Parliament and of the Council with regard to ecodesign requirements for glandless standalone circulators and glandless circulators integrated in products, amended by Commission Regulation (EU) No 622/2012 of July 11, 2012, Document 02009R0641-20170109. Available online: https://eur-lex.europa.eu/legal-content/EN/ TXT/?uri=CELEX\%3A02009R0641-20170109 (accessed on 27 November 2019).

26. Ferreira, F.J.T.E.; de Almeida, A.T. Energy Savings Potential Associated with Stator Winding Connection Mode Change in Induction Motors. In Proceedings of the XXII International Conference on Electrical Machines (ICEM), Lausanne, Switzerland, 04-07 September 2016; pp. 2775-2783.

27. Eurostat Data for the Industrial Consumers in Germany. Available online: http://ec.europa.eu/eurostat/ statistics-explained/index.php/Electricity_price_statistics\#Electricity_prices_for_industrial_consumers (accessed on 27 November 2019).

28. Pump Life Cycle Costs: A Guide to LCC Analysis for Pumping Systems, Executive Summary. Hydraulic Institute (Parsippany, NJ); Europump (Brussels, Belgium); Office of Industrial Technologies Energy Efficiency and Renewable Energy U.S. Department of Energy (Washington, DC). January 2001, pp. 1-19. Available online: https://searchworks.stanford.edu/view/4676735 (accessed on 27 November 2019). 
29. Waghmode, L.; Sahasrabudhe, A. A comparative study of life cycle cost analysis of pumps. In Proceedings of the ASME 2010 International Design Engineering Technical Conferences and Computers and Information in Engineering Conference (ASME 2010), Montreal, QC, Canada, 15-18 August 2010; Volume 6, pp. 491-500.

30. Rotating Electrical Machines-Part 30-2: Efficiency Classes of Variable Speed AC Motors (IE-Code); IEC TS 60034-30-2:2016; IEC: Geneva, Switzerland, 2016; Available online: https://webstore.iec.ch/publication/30830 (accessed on 27 November 2019).

31. Rotating Electrical Machines_Part 30-2: Efficiency Classes of Variable Speed AC Motors (IE-Code); Document 2/1709/NP; Standard draft; IEC: Geneva, Switzerland, 2013; Available online: https://www.iec.ch/dyn/

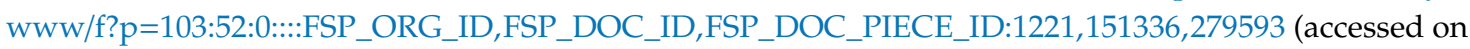
27 November 2019).

32. De Lima, W.I.B. Rare Earth Industry; Elsevier: Amsterdam, The Netherlands, 2015.

33. Dent, P. Rare earth elements and permanent magnets. J. Appl. Phys. 2012, 111. [CrossRef]

34. Goss, J.; Popescu, M.; Staton, D. A Comparison of an Interior Permanent Magnet and Copper Rotor Induction Motor in a Hybrid Electric Vehicle Application. In Proceedings of the IEEE International Electric Machines \& Drives Conference, EMDC, Chicago, IL, USA, 12-15 May 2013.

35. Ismagilov, F.R.; Vavilov, V.E.; Gusakov, D.V. Line-Start Permanent Magnet Synchronous Motor for Aerospace Application. In Proceedings of the IEEE International Conference on Electrical Systems for Aircraft, Railway, Ship Propulsion and Road Vehicles and International Transportation Electrification Conference, ESARS-ITEC, Nottingham, UK, 7-9 November 2018. [CrossRef]

36. Sorgdrager, J.; Wang, R.; Grobler, A.J. Multi-Objective Design of a Line-Start PM Motor Using the Taguchi Method. IEEE Trans. Ind. Appl. 2018, 54, 4167-4176. [CrossRef]

37. Kurihara, K.; Rahman, M.A. High-Efficiency Line-Start Interior Permanent-Magnet Synchronous Motors. IEEE Trans. Ind. Appl. 2004, 40, 789-796. [CrossRef]

38. Azari, M.N.; Mirsalim, M. Line-start permanent-magnet motor synchronisation capability improvement using slotted solid rotor. IET Electr. Power Appl. 2013, 7. [CrossRef]

39. Ferreira, F.J.T.; Leprettre, B.; De Almeida, A.T. Comparison of protection requirements in IE2-IE3-and IE4-class motors. IEEE Trans. Ind. Appl. 2016, 52, 3603-3610. [CrossRef]

40. Commission Regulation (EU) No 547/2012 of June 25, 2012 Implementing Directive 2009/125/EC of the European Parliament and of the Council with Regard to Ecodesign Requirements for Water Pumps. Available online: https:/eur-lex.europa.eu/legal-content/EN/TXT/?uri=CELEX\%3A32012R0547 (accessed on 27 November 2019).

41. Extended Product Approach for Pumps, Copyright (C) 2014 by Europump. Published by Europump. Available online: http://europump.net/uploads/Extended\%20Product \%20Approach\%20for\%20Pumps\%20\%20A\%20Europump\%20guide\%20(27OCT2014).pdf (accessed on 27 November 2019).

42. Lang, S.; Ludwig, G.; Pelz, P.F.; Stoffel, B. General Methodologies of Determining the Energy Efficiency Index of Pump Units in the Frame of the Extended Product Approach; EEMODS: Rio de Janeiro, Brazil, 2013. 